\title{
F-18 FDG PET/CT in Relapsing Polychondritis Patients with Initial Respirotory Symptoms: Imaging Features and Association with Pulmonary Function and Disease Activity
}

\author{
Jing-Wei Yi \\ the First Affiliated Hospital of Guangzhou Medical University \\ Peng Hou \\ the First Affiliated Hospital of Guangzhou Medical University \\ Jin-Ling Wang \\ the First Affiliated Hospital of Guangzhou Medical University \\ Jing Qi \\ Medical College of Wisconsin \\ Si-Yan Lin \\ the First Affiliated Hospital of Guangzhou Medical University \\ Min Wang \\ the First Affiliated Hospital of Guangzhou Medical University \\ Xin-Lu Wang ( 71lu@163.com) \\ the First Affiliated Hospital of Guangzhou Medical University
}

Research Article

Keywords: Relapsing polychondritis, 18F-FDG PET/CT, airway involvement, diagnosis

Posted Date: January 11th, 2022

DOI: https://doi.org/10.21203/rs.3.rs-1240149/v1

License: (c) (1) This work is licensed under a Creative Commons Attribution 4.0 International License. Read Full License 


\section{Abstract}

Background: To summarize F-18 fluorodeoxyglucose (FDG) positron emission tomography/computed tomography (PET/CT) imaging features of relapsing polychondritis (RP) and to evaluate the feasibility of imaging parameters in the estimation of pulmonary function and disease activity in a cohort of RP patients with airway involvement.

Methods: Thirty RP patients with respiratory symptoms who underwent PET/CT scans before corticosteroid treatment were included. Six patients underwent another post-therapeutic PET/CT scan. Imaging features were described by consensus, and FDG uptake values (SUV max $_{\text {, }}$ PET FDG Burden Score (PETFBS) and PETCTindex) either for global cartilages or for the airway were calculated to correlate with clinical symptoms, pulmonary functional parameters and serological inflammatory markers C-reactive protein (CRP) and erythrocyte sedimentation rate (ESR).

Results: Laryngo-tracheo-bronchial involvement was detected by PET/CT for all patients with increased FDG uptake in 28/30 patients. The incidence of positive PET was higher in segments with wall thickening ( $52.68 \%$ vs. $15.48 \%$ ) but was not associated with calcification or stenosis. A total of $46.7 \%$ ( $14 / 30)$ of patients presented with sole respiratory symptoms, while PET/CT revealed additional abnormalities in addition to laryngo-tracheo-bronchia. FDG uptake values negatively correlated with disease duration but not with fever. All FDG uptake values showed a positive correlation with FEV1/FVC, with the highest

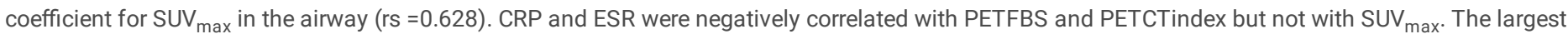
Spearman correlation coefficient resulted in PETFBS in the airway ( $r=0.67$ ). Re-examination PET/CT in 6 patients revealed partial therapeutic response $(n=$ $4)$, stable disease $(n=1)$ and progressive disease $(n=1)$.

Conclusion: PET/CT is a valuable tool for assessing RP with airway involvement, especially for patients who present with sole respiratory symptoms. SUV $\mathrm{V}_{\text {max }}$ and PETFBS have distinct advantages in the clinical evaluation of RP with respect to pulmonary function and disease activity.

\section{Background}

Relapsing polychondritis (RP) is a rare immune-mediated condition characterized by repeated inflammation of the affected cartilages and proteoglycan-rich tissues throughout the body ${ }^{[1,2]}$. Laryngotracheal involvement is the second most frequent initial feature and may cause life-threatening comorbidities ${ }^{[2-4]}$. However, the majority of RP patients with airway involvement were misdiagnosed at their first visit with a median time of delay to diagnosis of up to more than 10 years ${ }^{[1,4,5]}$. Our early studies ${ }^{[6-8]}$, along with other previous case reports or sporadic cases have shown that $18 \mathrm{~F}$-fluorodeoxyglucose positron emission


in the diagnosis and for therapeutic response monitoring ${ }^{[9-15]}$, with typical imaging characteristics of FDG uptake in the laryngo-tracheo-bronchial tree, often symmetrically.

On the other hand, we have encountered several cases with relatively low FDG uptake in the airway in our clinical practice, in keeping with the previous studies

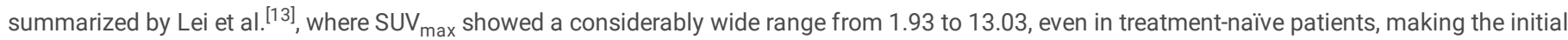
diagnosis ambiguous for low uptake patients. Moreover, patients who felt improved symptoms and inflammation may presented with increased SUV $\mathrm{max}_{\text {of }}$

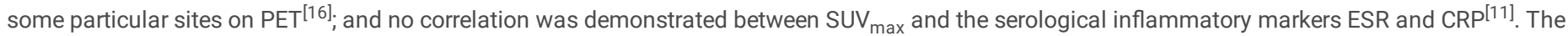
above-mentioned situation partly limits the utility of the current widely used parameter SUV $\mathrm{max}_{\text {in }}$ the diagnosis, evaluation of disease activity and treatment response of this rare systemic disease. In recent years, a new PET-based parameter developed by adding the visual score of each targeted site has been assessed in patients with Takaysu's arteritis to reflect the global inflammatory burden of the aterials, showing superior performance in the assessment of disease activity compared with regional SUV $_{\max }{ }^{[17-20]}$. However, whether it is valuable in RP patients is still unknown.

Accordingly, we conducted this retrospective study in a cohort of 30 treatment-naive patients in a respiratory center, which comprised the largest sample size to date, to investigate the feasibility and utility of PET/CT in evaluating RP patients with airway involvement in the scenario of imaging characteristics. Moreover, we aimed to explore the association of various PET parameters with clinical characteristics, serological inflammatory biomarkers and pulmonary function parameters.

\section{Materials And Methods}

\section{Study design and subject selection}

The study gained the approval of our institutional review board, and informed consent was waived for this retrospective study analysis. From January 2010 to April 2021, patients diagnosed with RP either histologically confirmed by biopsy or in accordance with either the criteria by McAdam's, Damiani and Levine's or Michet's criteria referred to our PET/CT center $(n=45)$ were included for this study. The exclusion criteria were: 1$)$ patients treated with corticosteroid therapy before PET/CT scan ( $n=13,11$ were previous diagnosed with RP, 2 was first diagnosed as RP clinically but was finally confirmed as tracheobronchial amyloidosis or rhinoscleroderma); 2 ) loss of Digital Imaging and Communications in Medicine (DICOM) information ( $\mathrm{n}=2$ ). Finally, 30 patients were included in this study.

\section{Protocol of PET/CT scans}

Patients need to fast for at least 6 hours and blood glucose levels should be controlled less than $11.1 \mathrm{mmol} / \mathrm{L}$. 18F-FDG of 3.70-5.55 MBq/kg was administered intravenously. Approximately $60 \mathrm{~min}$ (range: 45 to $105 \mathrm{~min}$ ) after 18F-FDG injection, a whole-body CT scan from the base of the skull to midthigh was performed, followed by a whole-body PET with the same range. The acquisition parameters were as follows: $140 \mathrm{kV}, 150 \mathrm{mAs}$, pitch $1.675,512 \times$ 
512 image matrix, slice thickness of $3.75 \mathrm{~mm}$, and a total of six or seven cradle positions with $3.5 \mathrm{~min} / \mathrm{cradle}$ position. All PET/CT studies were performed on an 8-section PET/CT scanner (Discovery ST 8, GE Healthcare, WI, USA). PET data were reconstructed with image matrix 128×128, and a two-dimensional ordered-subset expectation maximization (OSEM) algorithm.

\section{Image Analysis}

PET, CT, and fused PET/CT images were reviewed on the dedicated manufacturer's review workstation (Xeleris, Version No. 2.1753). Two board-certified nuclear medicine physicians (P. H. and J-W Y, with 9 and 6 years of PET/CT experience, respectively) independently analyzed the initial PET/CT images. Clinical information is available to readers. Discordant opinions were resolved by consensus.

PET imaging analysis included qualitative and quantitative analysis in the region of the nose, ears, larynx, tracheo-bronchia, ribs and peripheral joints. The degree of FDG uptake was visually assessed as visual score (VS) relative to mediastinum blood pool and liver uptake as: $0=$ no uptake; $1=$ slight uptake, but below the mediastinal blood pool; 2 = equal to or greater than the mediastinal blood pool, but below the liver; $3=$ equal to or greater than liver. Generally, VS $\geq$ 1 was applied for all the sites, as mentioned above. Furthermore, the distribution of FDG uptake should be in accordance with the shape of tracheo-bronchia and ribs. For nasal cartilage in which physiologic tracer uptake was commonly detected, VS combined with morphological changes was determined to be positive (see Supplementary Table 1, Additional file 1). For quantitative assessment, three PET parameters were calculated, namely, SUV max PET FDG Burden Score (PETFBS) and PETCTindex. SUV max $_{\text {was }}$ wefined as the highest SUV max in the chosen region. PETFBS reflecting the whole burden of FDG uptake was the summation of VS of the targeted sites. PETCTindex, aiming to display the heterogeneity of metabolism and structure, was defined as the number of PETpositive lesions/(number of PET-positive lesions + number of CT-positive lesions). Each parameter was measured both in the laryngo-tracheo-bronchia (hereafter termed SUV maxairway, $_{\text {PETFBS }}$ airway and PETCTindex ${ }_{\text {airway }}$ ) and around the region of the nose, ears, larynx, tracheo-bronchia, ribs and peripheral

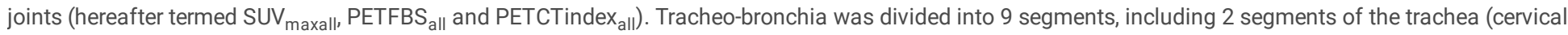
and thoracic) and 7 main branch segments (bilateral main-stem bronchi; 3 right lobar bronchi and 2 left lobar bronchi). Illustration of the segmentation of the tracheo-bronchia is shown in Supplementary Fig.1 (Additional file 2), and a detailed definition and example of how to measure these parameters is shown in Supplementary Fig.2 (Additional file 3).

The CT component was used to evaluate the morphology of the cartilage, mainly for the assessment of soft-tissue swelling, prevalence of calcification and structural destruction. Airway wall thickening was defined as thickness of the involved segments of the trachea or main bronchi greater than 2 mm ${ }^{\text {[21] }}$

\section{Statistical analysis}

Descriptive statistics are shown as the mean \pm standard deviation or the median (interquartile range [IQR]). The chi-square test was applied to evaluate the relationship between PET and CT imaging characteristics of the airway. Nonparametric Mann-Whitney U tests were used to compare airway wall thickness and SUV ${ }_{\text {max }}$ between patients with or without posterior wall thickening of the trachea. Spearman's rank correlation coefficient (rs) was calculated to examine the correlations between PET/CT parameters and clinical data (disease duration, fever), pulmonary function parameters (FEV1\%predicted, FVC\%predicted and FEV1/FVC), and nonspecific inflammatory markers (CRP and ESR). All tests were two-sided, and p values of 0.05 or less denoted statistical significance. Analysis was performed using SPSS 20.0 (SPSS Inc., Chicago, IL, USA).

\section{Results}

\section{Clinical characteristics}

Thirty patients ( 19 males and 11 females, mean age 47士10) were enrolled in the study. Nineteen patients were diagnosed through biopsy (flexible bronchoscopy (FBO), $n=4$; auricular cartilage biopsy, $n=13$; nasal cartilage biopsy, $n=1$; one patient had positive bronchoscopy and auricular biopsy results), and the other 11 patients were diagnosed with clinical presentations assessed by clinicians. The duration between symptom onset and diagnosis ranged from 1 to 84 months (median, 6 months). All patients visited doctors due to respiratory symptoms, which were the only symptoms in 16 patients. The three most common signs were chronic cough (93.3\%) and shortness of breath (73.3\%), followed by expectoration (60.0\%). Other symptomatic sites included the ears (30.0\%), joints (20.6\%), nose (20.0\%), eyes (10.0\%) and skin (3.3\%) in 14 patients (46.7\%) during subsequent careful physical examinations. Seven (23.3\%) patients presented with fever. Pulmonary functional tests (PFTs) were successfully performed in 24 patients. Most patients (75\%) demonstrated severe/extreme severe pulmonary function abnormalities, with obstructive and mixed ventilation dysfunction in 9 and 9 patients, respectively. The erythrocyte sedimentation rate (ESR) and C reaction protein (CRP) increased significantly in 16/23 and 18/24 patients, respectively. The clinical characteristics of all 30 patients are listed in Table 1.

\section{Table 1 Clinical Characteristics of all 30 RP patients}




\begin{tabular}{|c|c|c|}
\hline Characteristic & Number of patients & Value \\
\hline Mean age (yr),mean $\pm S D$ & 30 & $46.87 \pm 10.45$ \\
\hline Sex & 30 & \\
\hline Male & & $19(63.3 \%)$ \\
\hline Female & & $11(36.7 \%)$ \\
\hline Chief complain(n,\%) & 30 & \\
\hline Cough & & $28(93.3 \%)$ \\
\hline Fever & & $7(23.3 \%)$ \\
\hline Pain of chest/Chest tightness & & $5(16.7 \%)$ \\
\hline Shortness of the breath & & $22(73.3 \%)$ \\
\hline Hoarseness & & $12(40.0 \%)$ \\
\hline Expectoration & & $18(60.0 \%)$ \\
\hline Other symptomatic sites(n,\%) & 30 & \\
\hline Ears & & $9(30.0 \%)$ \\
\hline Joints & & $7(20.6 \%)$ \\
\hline Nose & & $6(20.0 \%)$ \\
\hline Skin & & $1(3.3 \%)$ \\
\hline Eyes & & $3(10 \%)$ \\
\hline $\begin{array}{l}\text { Duration of symptoms(m) } \\
\text { (median[IQR]) }\end{array}$ & 30 & $6[3,15]$ \\
\hline \multicolumn{3}{|l|}{ Laboratory parameters } \\
\hline WBC $\left({ }^{\star} 10^{9} / \mathrm{L}\right)($ median[IQR]) & 27 & $9.4[7.7,12.27]$ \\
\hline NEU (\%) & 27 & $71.11 \pm 12.50$ \\
\hline $\mathrm{HB}(\mathrm{g} / \mathrm{L})$ & 25 & $120.3 \pm 17.58$ \\
\hline PLT $\left({ }^{\star} 10^{9} / \mathrm{L}\right)($ median[IQR]) & 25 & $312.0[238,416]$ \\
\hline ESR (mm/L) (median[IQR]) & 24 & $61.0[21.75,118.3]$ \\
\hline CRP (mg/dL) (median[IQR]) & 23 & $2.11[0.52,12.72]$ \\
\hline $\mathrm{RF}(\mathrm{IU} / \mathrm{ml})$ (median[IQR]) & 24 & $7[2.32,10.85]$ \\
\hline Lung function test & 24 & \\
\hline Normal & & $1(4.16 \%)$ \\
\hline Mild OVD & & $3(12.5 \%)$ \\
\hline Medium OVD & & $2(8.33 \%)$ \\
\hline Severe/extremely severe & & $18(75.0 \%)$ \\
\hline
\end{tabular}

Page $4 / 15$ 


\begin{tabular}{|c|c|c|}
\hline \multicolumn{2}{|l|}{ OVD } & $9(37.5 \%)$ \\
\hline \multicolumn{2}{|l|}{ MVD } & $9(37.5 \%)$ \\
\hline \multicolumn{3}{|l|}{ Biopsy } \\
\hline Bronchoscopic biopsy & 24 & 5 \\
\hline Biopsy of auricular cartilage & 20 & 14 \\
\hline Biopsy of nasal cartilage & 2 & 1 \\
\hline
\end{tabular}

WBC white blood cell count, NEU neutrophil, HB hemoglobin, PLT platelet count, ESR erythrocyte sedimentation rate, CRP C reaction protein, RF rheumatoid factors, FEV1, forced expiratory volume in 1 second, FVC, forced vital capacity, CTX, Cyclophosphamide.OVD obstructive ventilation dysfunction,MVD mixed ventilation dysfunction

Normal range: WBC (*109/L) 4.0 to 10.0, NEU (\%) 40.0 to 70.0, HB (g/L) 110 to 150 (female) or 120-160 (male), PLT (*109/L) 100 to 400, ESR (mm/L) 0 to 20, $\mathrm{CRP}(\mathrm{mg} / \mathrm{dL}) 0$ to $0.6, \mathrm{RF}(\mathrm{IU} / \mathrm{ml})<20$.

\section{PET/CT imaging features}

The PET/CT presentations of each patient are outlined in Table 2. As demonstrated, laryngo-tracheo-bronchial involvement was shown on PET in 93.3\% $(28 / 30)$ of patients and $100 \%(30 / 30)$ on CT. Overall, PET/CT was positive in all 30 patients for at least one site, $\geq 2$ or 3 sites of abnormalities in 29 (96.7\%) and $23(76.7 \%)$ of 30 patients, respectively. The representative figures are shown in Fig. 1. The frequency and mean SUV $\mathrm{max}_{\text {of }}$ each site of abnormalities are

shown in Fig. 2. As shown, the SUV $\mathrm{max}_{\text {max }}$ of each involved site was 4.04 [2.62, 5.11], 4.50 [3.40, 5.20], 2.90 [2.40,3.60], 3.55 [3.10, 4.25], 4.00 [3.02,4.98], and 2.90 $[2.60,4.95]$ for the tracheobronchial tree, laryngeal, auricular, costal, nasal cartilages and peripheral joints, respectively. In 14 patients who presented with sole respiratory symptoms, PET/CT revealed multiple lesions in the auricles $(71.4 \%, 10 / 14)$, ribs $(50 \%, 7 / 14)$, peripheral joints $(21.4 \%, 3 / 14)$ and nasal cartilage $(14.3 \%, 2 / 14)$ apart from laryngo-tracheo-bronchia $(100 \%, 14 / 14)$.

\section{Table 2 PET/CT Findings and Biopsy Results of 30 Patients with RP}




\begin{tabular}{|c|c|c|c|c|c|c|c|c|c|}
\hline \multirow{2}{*}{$\begin{array}{l}\text { Patient } \\
\text { No./Sex/Age }\end{array}$} & \multirow{2}{*}{$\begin{array}{l}\text { Other } \\
\text { symptomatic } \\
\text { sites besides } \\
\text { airway }\end{array}$} & \multicolumn{3}{|l|}{ PET } & \multicolumn{3}{|l|}{ CT } & \multicolumn{2}{|c|}{ Biopsy } \\
\hline & & $\begin{array}{l}\text { Predominant } \\
\text { Sites }\end{array}$ & $\mathrm{SUV}_{\max }$ & $\begin{array}{l}\text { Other sites } \\
\text { and } \text { SUV }_{\max }\end{array}$ & Sites & Abn. & $\begin{array}{l}\text { Other } \\
\text { sites } \\
\text { and } \\
\text { abn. }\end{array}$ & FOB & Ear \\
\hline $1 / \mathrm{M} / 68$ & l & $1-4$ & $\begin{array}{l}4.2,2.8,4.5 \\
3.1\end{array}$ & & $1 / 3$ & $22 \sim 24 / 21$ & & + & / \\
\hline 2/M/55 & / & $1,2-4$ & $\begin{array}{l}3.0,4.2,4.9 \\
4.8\end{array}$ & & $1 / 2 / 3$ & $23 / 21 / 21,23$ & & - & $\stackrel{+}{(\mathrm{L})}$ \\
\hline $3 / M / 61$ & Fever & $1-3,6$ & $\begin{array}{l}4.7,3.5,4.4 \\
6.4\end{array}$ & $7: 5.0$ & $1 / 6$ & $22 \sim 24,21$ & $7: 0.8 \mathrm{~cm}$ & / & / \\
\hline 4/M/58 & Fever & $1-3$ & $5.3,4,4,6.4$ & & $1 / 2 / 3$ & $22 \sim 24 / 21 / 21,24$ & $7: 1.1 \mathrm{~cm}$ & - & $\stackrel{+}{(L)}$ \\
\hline $5 / \mathrm{M} / 35$ & Eyes, fever & $1,2,4$ & $10.4,7.0,2.6$ & Muscle: 4.3 & $1 / 2$ & $22 \sim 24 / 21,24$ & & / & + \\
\hline $6 / \mathrm{M} / 52$ & l & 2,4 & $4.5,3.2$ & $\begin{array}{l}\text { Nasopharynx囚 } \\
5.7\end{array}$ & 1 & $22 \sim 24$ & & / & $\stackrel{+}{(\mathrm{L})}$ \\
\hline $7 / M / 49$ & $\begin{array}{l}\text { Ribs, rash, } \\
\text { fever }\end{array}$ & $1-4$ & $\begin{array}{l}5.2,5.2,4.9 \\
3.9\end{array}$ & BM:3.9 & $1 / 2 / 3$ & $22 \sim 24 / 21 / 21$ & & - & - \\
\hline $8 / F / 50$ & l & $1,2,4,5$ & $5.1,3.4,2.3,3.0$ & & $1 / 5$ & $22 \sim 24 / 21$ & & - & $\begin{array}{l}+ \\
(\mathrm{R})\end{array}$ \\
\hline 9/F/44 & l & $1-4$ & $6.1,2.8,5.7,1.9$ & $7: 3.2$ & $1 / 2 / 3$ & $22 \sim 24 / 21 / 21,23$ & $7: 0.9 \mathrm{~cm}$ & - & $\stackrel{+}{(L)}$ \\
\hline 10/M/36 & $\begin{array}{l}\text { Right ear, } \\
\text { eyes, fever, }\end{array}$ & $1,2,4,5$ & $3.5,5.0,3.4,3.1$ & & $1 / 2 / 4 / 5$ & $22,23 / 21,24,25 / 21 / 23$ & & + & / \\
\hline $11 / F / 43$ & Joints & 2,4 & $2.9,2.2$ & & $1 / 2$ & $22 \sim 24 / 21,24,25$ & & / & $\overline{(L)}$ \\
\hline \multirow[t]{3}{*}{ 12/M/41 } & \multirow[t]{3}{*}{ Chest wall } & \multirow[t]{3}{*}{$1-3$} & \multirow[t]{3}{*}{$5.2,3.6,4.7$} & $7: 4.5$ & \multirow[t]{3}{*}{$1 / 2$} & \multirow[t]{3}{*}{$22 \sim 24 / 25$} & \multirow[t]{3}{*}{$7: 1.0 \mathrm{~cm}$} & \multirow[t]{3}{*}{-} & \multirow{3}{*}{$\stackrel{+}{(\mathrm{L})}$} \\
\hline & & & & BM:8.4 & & & & & \\
\hline & & & & PI: 10.4 & & & & & \\
\hline 13/M/37 & / & $1,2,4,5$ & $5.6,3.5,5.4,5.0$ & $7: 3.4$ & $1 / 2 / 4 / 5$ & $22,23,24 / 21 / 21,22 / 21$ & $7: 1.0 \mathrm{~cm}$ & - & - \\
\hline $14 / F / 50$ & $\begin{array}{l}\text { Ears, nose, } \\
\text { eyes }\end{array}$ & / & / & & $1 / 4 / 5$ & $22 \sim 24 / 21,22 / 26$ & & + & / \\
\hline $15 / F / 50$ & Fever & $1-4$ & $4.9,3.8,3.4,1.7$ & & $1 / 3$ & $22 \sim 24 / 21$ & & - & + \\
\hline $16 / F / 42$ & / & $1-4$ & $3.7,3.4,4.3,3.2$ & $7: 3.5$ & $1 / 2$ & $22 \sim 24 / 21,24$ & $7: 0.7$ & - & / \\
\hline $17 / M / 45$ & $\begin{array}{l}\text { Ears, ribs, } \\
\text { nose, fever }\end{array}$ & $1-4$ & $5.0,3.9,5.5,2.5$ & 7:3.6 & $1 / 2 / 3$ & $22 \sim 24 / 21 / 21$ & $7: 0.7 \mathrm{~cm}$ & - & $\stackrel{+}{(L)}$ \\
\hline 18/M/60 & l & 2 & 2.8 & $7: 2.5$ & 1 & $22 \sim 24$ & $7: 0.7 \mathrm{~cm}$ & - & $\stackrel{+}{(L)}$ \\
\hline 19/M/51 & Fever & 1,3 & $1.8,3.2$ & $7: 4.3$ & 1 & $22 \sim 24$ & $7: 0.8 \mathrm{~cm}$ & - & / \\
\hline $20 / M / 55$ & l & 1,4 & $4.5,2.4$ & $7: 4.3$ & 1 & 23,24 & $7: 0.8 \mathrm{~cm}$ & - & / \\
\hline $21 / M / 27$ & I & $1,2,4$ & $4.0,4 \cdot 5,2.7$ & & $1 / 2$ & $23,24 / 21,24$ & & I & $\overline{(L)}$ \\
\hline $22 / \mathrm{M} / 46$ & $\begin{array}{l}\text { Left ear, } \\
\text { nose, fever }\end{array}$ & $1,4,6$ & $4.1,2.8,2.4$ & $7: 6.4$ & 1 & $22 \sim 24$ & $7: 1.2 \mathrm{~cm}$ & - & $\overline{(L)}$ \\
\hline \multirow[t]{2}{*}{ 23/M/49 } & \multirow[t]{2}{*}{ / } & \multirow[t]{2}{*}{3} & \multirow[t]{2}{*}{5.5} & $\begin{array}{l}\text { Sacroiliac } \\
\text { joint } \ 2.8\end{array}$ & \multirow[t]{2}{*}{$1 / 3$} & \multirow[t]{2}{*}{$22 \sim 24 / 23$} & & \multirow[t]{2}{*}{+} & \multirow[t]{2}{*}{ (R) } \\
\hline & & & & Musles $₫ 4.6$ & & & & & \\
\hline $24 / F / 52$ & l & $2-4,6$ & $3.3,3.3,4.1,3.5$ & BM: 4.1 & $1 / 4$ & $22,23 / 21$ & & / & / \\
\hline 25/F/32 & Fever & 1 & 3.1 & & 1 & $22 \sim 24$ & $7: 0.7 \mathrm{~cm}$ & + & / \\
\hline $26 / F / 52$ & l & $1-3$ & $3.2,2.3,5.2$ & & $1 / 2$ & $22 \sim 24 / 25$ & & - & $\stackrel{+}{(R)}$ \\
\hline $27 / F / 29$ & Ears, nose & $1,2,4$ & $2.2,3.7,3.6$ & Muscle2.7 & $1 / 2 / 4$ & $23 / 21,24 / 21$ & & - & $\stackrel{+}{(\mathrm{L})}$ \\
\hline $28 / F / 56$ & / & 1,6 & $2.3,3.0$ & & $1 / 6$ & $22,23,24 / 21$ & & - & + \\
\hline
\end{tabular}

Page 6/15 


\begin{tabular}{|c|c|c|c|c|c|c|c|c|c|}
\hline $29 / M / 26$ & $\begin{array}{l}\text { Ears, left } \\
\text { ribs, nose, } \\
\text { fever }\end{array}$ & $1,2,4,5$ & $4.1,3.2,2.9,4.9$ & $\begin{array}{l}\text { Sublingual } \\
\text { and salivary } \\
\text { gland } ₫ 22.8\end{array}$ & $1 / 4 / 5$ & $23 / 21 / 21$ & & - & / \\
\hline $30 / F / 55$ & Ears & 1,2 & $5.6,7.2$ & $7: 2.5$ & $1 / 2$ & $22 / 23,21 / 22 / 24$ & 7:0.8 & - & $\stackrel{+}{(\mathrm{R})}$ \\
\hline
\end{tabular}

1.tracheobronchial tree; 2.larynx; 3.costicartilage; 4.auricular cartilage; 5.nasal cartilage; 6.joint; 7.mediastinal lymph nodes

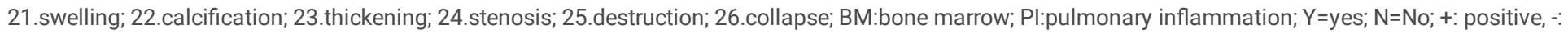
negative; /: undone; FOB: Fiberoptic bronchoscope

\section{Association of 18F-FDG activity and morphological characteristics of the airway}

A total of 111 tracheo-bronchial segments (34 in the trachea, 28 in the main bronchi, and 49 lobar bronchi) were positive among all 270 analyzed segments. The majority of FDG-avid segments showed wall thickening (98/111, 88.3\%), followed by calcification (51/111, 45.9\%), stenosis (42/111, 37.8\%) and normal structure $(12 / 111,10.8 \%)$. Increased FDG uptake was associated with thickened wall $(p=0.000)$ but not with calcification $(p=0.076)$ or stenosis $(p=0.230)($ Fig. 3a).

In addition, twenty-nine patients with 58 segments of the trachea were analyzed except for one patient whose airway was normal on CT. Overall, 22 segments of the trachea demonstrated circumferential thickening, whereas sparing of the posterior membranes was found in the remaining 36 segments. The FDG activity and wall thickness were significantly increased in the posterior wall involved group than in segments with spared posterior wall (SUV max: 4.14 [3.16, $5.00]$ vs. 1.98 [1.49, 3.43], $p<0.001$; wall thickness: 0.50 [0.47, 0.67] vs. 0.43 [0.32, 0.55], $p=0.014$ ) (Fig. 3b,c). Representative cases are shown in Fig. 4.

For the larynx, soft-tissue swelling $(13 / 24,54.2 \%)$, subglottic stenosis $(11 / 24,45.8 \%)$ and destroyed/calcified laryngeal cartilage $(4 / 24,16.7 \%)$ were the main findings on CT of the affected larynx.

\section{General symptoms and PET/CT}

General symptoms, including disease duration and fever, were compared with PET/CT imaging. As shown in Fig. 5, all PET parameters showed a statistically significant negative correlation with disease duration. Among them, the correlation coefficient was highest for PETFBS either in the airway ( $r s=0.657$ ) or in the whole body $(r s=0.517$ ). In contrast, there was no correlation between patients with fever and PET parameters (see Supplementary Table 2, Additional file 4).

\section{Correlation of chest PET images with pulmonary function test}

Table 3 demonstrates that there were statistically significant positive correlations between FEV1/FVC and PET parameters of the airway and a weak positive correlation between FEV1\% predicted values and SUV $\max (r s=0.413)$. However, no correlation was found between PET parameters and FVC\% predicted values. The coefficient was highest in $\operatorname{SUV}_{\max }(r s=0.628)$ compared with PETCTindex $(r s=0.519)$ or PETFBS $(r s=0.477)$.

\section{Table 3 correlation between PET paramters and pulmonary function test}

\begin{tabular}{|c|c|c|c|c|c|c|}
\hline & \multicolumn{2}{|c|}{ FEV1/FVC } & \multicolumn{2}{|c|}{ FEV1\% predicted } & \multicolumn{2}{|c|}{ FVC\% predicted } \\
\hline & rs & $\mathrm{p}$ & rs & $\mathrm{p}$ & rs & $\mathrm{p}$ \\
\hline SUV $_{\text {maxairway }}$ & 0.628 & $0.001^{\star *}$ & 0.413 & $0.045^{*}$ & 0.120 & 0.576 \\
\hline PETFBS $_{\text {airway }}$ & 0.477 & $0.018^{*}$ & 0.246 & 0.247 & 0.059 & 0.783 \\
\hline PETCTindex ${ }_{\text {airway }}$ & 0.611 & $0.002^{* *}$ & 0.404 & 0.050 & 0.150 & 0.458 \\
\hline
\end{tabular}

\section{Disease activity and PET imaging}

A correlation matrix (Fig. 6a) was drawn to compare serological inflammatory activity indicators and PET parameters. As demonstrated, PETFBS airway, having a moderate Spearman correlation coefficient with both ESR and CRP, was superior in correlating with serological inflammatory markers, suggesting that the latter indicators may work better in the assessment of airway inflammation rather than whole-body evaluation. On the other hand, SUV $\mathrm{max}_{\text {, }}$ either in the airway or in the whole body, correlated with neither ESR nor CRP.

Six patients underwent a second PET/CT scan during follow-up (medium period: 5 months, range: 3-15 months). Five patients showed decreased SUV maxall and PETFBS ${ }_{\text {all }}, 4$ of whom had consistently improved symptoms, and the other patient was stable in clinical evaluation. The other patient evaluated as having

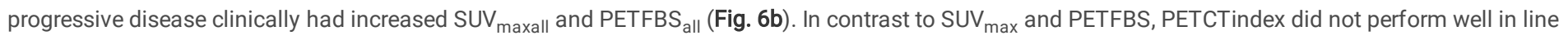
with clinical disease evaluation. 


\section{Discussion}

In the present study, we evaluated F-18 FDG PET/CT imaging characteristics and correlated imaging data with clinical information, pulmonary function and nonspecific inflammatory markers in a cohort of RP patients with symptomatic airway involvement. There were three major findings. First, isolated respiratory symptoms could be the only manifestation in nearly half of all RP-related symptomatic airway-involved cases. PET/CT established the diagnosis of airway involvement in all patients and revealed additional sites of abnormalities in more than $70 \%$ of the cases. Second, FDG uptake of the tracheo-bronchia was associated with wall thickness and disease duration. The posterior wall of the trachea can be affected in as many as $40 \%$ of segments. Third, the SUV max $_{\text {of }}$ the airway was superior in correlation with pulmonary function parameters compared with other PET parameters but not with ESR and CRP. On the other hand, serological inflammatory markers moderately correlated with the inflammatory burden parameter PETFBS, especially PETFBS in the airway. These findings not only support the promising role of F-18 FDG PET/CT in identifying disease extent and describing the disease with respect to pathophysiology but also highlight the potential of utilizing PETFBS to assess disease activity.

The diagnosis of RP remains a challenge attributable to insidious and variable symptoms ${ }^{[4]}$. Growing research effort of PET/CT has displayed potential for this non-invasive modality for diagnosing and evaluating the extent of the disease, especially for evaluating tracheobronchial involvement ${ }^{[15]}$. In our series, approximately half of the patients showed only respiratory symptoms that were easily misdiagnosed as respiratory disease, and PET/CT helped establish the diagnosis by demonstrating multiple organs involvement in more than $70 \%$ of the cases. The three most commonly affected sites were the tracheobronchia, followed by the larynx and auricular cartilages, which are different from the results of previous studies ${ }^{[11,15]}$. This discrepancy may be due to the difference in patients' origin compared to all our patients from a respiratory center.

Further assessment of the airway demonstrated positive PET results of PET in all but two patients with diffuse calcification in the tracheobronchial wall. As is known, RP involves the inflammatory edema of the airway during the active phase, followed by malacia, which is secondary to cartilage destruction, and finally stenosis due to fibrous replacement of the impaired cartilage ${ }^{[2]}$. Therefore, typical pulmonary CT findings of RP include airway wall thickening, tracheal malacia, calcification and airway stenosis ${ }^{[21,22]}$. Thickening of the airway wall is commonly used as an index for activity. Our study showed that the incidence of positive FDG uptake was higher in segments with wall thickness, which partially supported wall thickness as an inflammatory indicator in clinical practice. Nevertheless, there is significant disparity in the extent of thickened airway walls between our study and previous results. Sparing of the posterior wall due to a lack of cartilage in the posterior part of the trachea was considered highly typical for the diagnosis of RP in previous studies ${ }^{[21-25]}$. However, in our current study, 22/58 segments of the trachea showed circumferential thickening, including the posterior membranous part, along with higher FDG uptake. In fact, the posterior side of the trachea was also observed in 2 of seven patients with airway wall thickening in Lin's research ${ }^{[26]}$. These impressive findings suggest that the extent of tracheal involvement is not a credible sign for differential diagnosis and may vary due to different degrees of inflammation.

Pulmonary function tests are essential for assessing respiratory involvement and evaluating the severity of RP in patients; however, spirometry is an effortdependent maneuver, and sometimes it is difficult and dangerous to perform for patients with severe airway obstruction. To the best of our knowledge, there is no report evaluating the correlation between F-18 FDG PET/CT and pulmonary function tests in patients with RP. Our results showed a moderate positive correlation between FEV1/FVC and all PET parameters, including SUV maxairway, PETFBS airway $_{\text {and PETCTindex }}$ airway, while FEV1\% predicted value was weakly associated with SUV maxairway $_{\text {and PETCTindex }}$ airway, indicating that FDG PET parameters, especially SUV max of the airway, may be a surrogate for assessing the severity of obstruction for patients who cannot tolerate pulmonary function tests. One explanation for the positive correlation may be that a lower SUV $\mathrm{V}_{\text {max }}$ suggests a longer disease course, as demonstrated in our cohort, and more fibrotic lesions; thus, pulmonary function is worse.

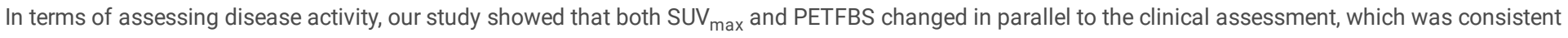
with previous results ${ }^{[11,13,15]}$. Apart from imaging markers, the nonspecific serological markers ESR and CRP are routinely used in clinical practice. Our current study revealed consistent results with a previously described study that these two markers did not show any correlation with SUV $_{\text {max }}{ }^{[11]}$, either for the whole body or for the airway. In contrast, both PETFBS and PETCTindex were positively correlated with both ESR and CRP, with a higher coefficient for the former.

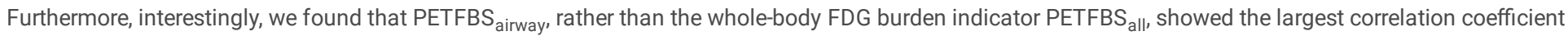
with nonspecific serological markers, suggesting that the ESR and CRP may be more appropriate for reflecting disease activity of the airway. Despite the fact that adding PET visual scores of the whole body to assess inflammatory activity has been adopted in Takaysu's arteritis patients in many studies ${ }^{[17-20]}$, this is the first study to adopt such method in RP patients. Further advanced investigations with larger sample sizes are required to verify the performance of this method for the assessment of disease activity.

There are some limitations of the study. First, histopathology was not available for all lesions, which may misjudge the pathological foci; thus, the calculation of PETFBS may be influenced. However, this condition can be found in many other multisystemetic diseases, such as Langerhans cell histiocytosis and IgG-4related disease. PET/CT does improve confidence in the diagnosis clinically. Second, as a retrospective study, clinical data, such as past glucocorticoid therapy long ago, may not be traced for all patients and may have influenced the results. However, at least three days off of glucocorticoids was recommended according to recent procedural recommendations of several European and American societies ${ }^{\text {[27] }}$. To our knowledge, no patients in our cohort underwent glucocorticoid treatment during the last month. Third, expiratory CT was not performed because it is not a standard procedure for routine PET/CT acquisition; thus, some signs, such as air trapping and tracheal malacia, could not be analysed.

\section{Conclusions}

In conclusion, PET/CT is a powerful tool in aiding in the assessment of RP with airway involvement, especially for patients who present with sole respiratory symptoms. Among the three PET parameters, PETFBS and PETindex, particularly PETFBS of the airway, reflect disease duration and activity in patients with 
RP more appropriately than SUV max $_{\text {. Nevertheless, the SUV }}$ max of the airway showed a moderate positive correlation with the FEV1/FVC ratio, suggesting that it is a good surrogate for evaluating the severity of obstruction. Further studies are warranted to clarify the role of PET/CT in monitoring this rare disease.

\section{Abbreviations}

RP: Relapsing polychondritis

F-18 FDG PET/CT: F-18 fluorodeoxyglucose (FDG) positron emission tomography/computed tomography

CRP: C-reactive protein

ESR: Erythrocyte sedimentation rate

SUV『Standard uptake value

PETFBS: PET FDG Burden Score

FEV1: Forced expiratory volume in the first second

FVC: Forced vital capacity

\section{Declarations}

\section{Availability of data and materials}

The data that supported the findings of this study are available on request from the corresponding author. The data are not publicly available due to privacy or ethical restrictions.

\section{Acknowledgements}

Not applicable.

\section{Funding}

None.

\section{Author's information}

Jing-Wei Yi: ivyjw@163.com; Peng Hou: pphouhou@sina.com; Jin-Ling Wang: drjlwang@126.com; Jing Qi: jqi@chw.org; Min Wang: 928939198@qq.com; SiYan Lin: 416320431@qq.com; Xin-Lu Wang: 71lu@163.com

\section{Author's contributions}

Y.J-W designed the study and wrote the paper. H.P, L.S-Y and W.M performed the data collection. W.X-L revised the design. W.J-L and Q.J evaluated the data and revised the paper. The authors read and approved the final manuscript.

\section{Availability of data and materials}

The datasets supporting the conclusions of this article are available from the corresponding author on reasonable request.

\section{Ethics declarations}

The study gained the approval of our institutional review board(2020-k-17) and the informed consent was waived for this retrospective study analysis.

\section{Consent for publication}

All patients have approved the manuscript and agree with the publication.

\section{Competing interests}

The authors declare that there are no financial or non-financial competing interests.

\section{References}

1. Hazra N, Dregan A, Charlton J, Gulliford MC, D'Cruz DP. Incidence and mortality of relapsing polychondritis in the UK: a population-based cohort study. Rheumatology. 2015;54:2181-7.

2. Kingdon J, Roscamp J, Sangle S, D'Cruz D. Relapsing polychondritis: a clinical review for rheumatologists. Rheumatology. 2018;57:1525-32. 
3. Dion J, Costedoat-Chalumeau N, Sene D, Cohen-Bittan J, Leroux G, Dion C, et al. Relapsing Polychondritis Can Be Characterized by Three Different Clinical Phenotypes: Analysis of a Recent Series of 142 Patients. Arthritis Rheumatol. 2016;68:2992-3001.

4. Zhang L, Wu TG, He YJ, Guo JY, Han LS, Lu JM, et al. Diagnosing relapsing polychondritis remains a common challenge: experience from a Chinese retrospective cohort. Clin Rheumatol. 2020.39:2179-84.

5. Ferrada M, Rimland CA, Quinn K, Sikora K, Kim J, Allen C, et al. Defining Clinical Subgroups in Relapsing Polychondritis: A Prospective Observational Cohort Study. Arthritis Rheumatol. 2020.72:1396-1402

6. Deng H, Chen P, Wang L, Li X, Yi J. Relapsing polychondritis on PET/CT. Clin Nucl Med. 2012;37:712-5.

7. Wang J, Li S, Zeng Y, et al. (1)(8)F-FDG PET/CT is a valuable tool for relapsing polychondritis diagnose and therapeutic response monitoring. Ann Nucl Med. 2014;28:276-84.

8. Li M, Zeng Y, Xie X, Wang J. A case of relapsing polychondritis solely presenting with chronic cough. Int J Clin Exp Med, 2017;10: 16745-9.

9. Nishiyama Y, Yamamoto Y, Dobashi H, Kameda T, Satoh K, Ohkawa M. [18F]fluorodeoxyglucose positron emission tomography imaging in a case of relapsing polychondritis. J Comput Assist Tomogr. 2007;31:381-3.

10. De Geeter F, Vandecasteele SJ. Fluorodeoxyglucose PET in relapsing polychondritis. N Engl J Med. 2008; 358:536-7.

11. Yamashita $H$, Takahashi H, Kubota K, Ueda Y, Ozaki T, Yorifuji H, et al. Utility of fluorodeoxyglucose positron emission tomography/computed tomography for early diagnosis and evaluation of disease activity of relapsing polychondritis: a case series and literature review. Rheumatology. 2014;53:1482-90.

12. Lei W, Zeng DX, Chen T, Jiang JH, Wang CG, Zhu YH, et al. FDG PET-CT combined with TBNA for the diagnosis of atypical relapsing polychondritis: report of 2 cases and a literature review. J Thorac Dis. 2014;6:1285-92.

13. Lei W, Zeng H, Zeng DX, Zhang B, Zhu YH, Jiang JH, et al. (18)F-FDG PET-CT: a powerful tool for the diagnosis and treatment of relapsing polychondritis. Br J Radiol. 2016;89:20150695.

14. Kaida H, Ishii K, Hanada S, Tohda Y, Murakami T. Incidental Case of Relapsing Polychondritis Detected by 18F-FDG PET/CT. Clin Nucl Med. 2018;43:2527.

15. Sharma A, Kumar R, Mb A, Naidu G, Sharma V, Sood A, et al. Fluorodeoxyglucose positron emission tomography/computed tomography in the diagnosis, assessment of disease activity and therapeutic response in relapsing polychondritis. Rheumatology. 2020;59:99-106.

16. Zeng Y, Li M, Chen S, Lin L, Li S, He J, et al. Is (18)F-FDG PET/CT useful for diagnosing relapsing polychondritis with airway involvement and monitoring response to steroid-based therapy? Arthritis Res Ther. 2019;21:282.

17. Grayson PC, Alehashemi S, Bagheri AA, Civelek AC, Cupps TR, Kaplan MJ, et al. (18) F-Fluorodeoxyglucose-Positron Emission Tomography As an Imaging Biomarker in a Prospective, Longitudinal Cohort of Patients With Large Vessel Vasculitis. Arthritis Rheumatol. 2018;70:439-49.

18. Kang F, Han Q, Zhou X, Zheng Z, Wang S, Ma W, et al. Performance of the PET vascular activity score (PETVAS) for qualitative and quantitative assessment of inflammatory activity in Takayasu's arteritis patients. Eur J Nucl Med Mol Imaging. 2020;47:3107-17.

19. Banerjee S, Quinn KA, Gribbons KB, et al. Effect of Treatment on Imaging, Clinical, and Serologic Assessments of Disease Activity in Large-vessel Vasculitis. J Rheumatol. 2020;47:99-107.

20. Rimland CA, Quinn KA, Rosenblum JS, Schwartz MN, Bates Gribbons K, Novakovich E, et al. Outcome Measures in Large Vessel Vasculitis: Relationship Between Patient-, Physician-, Imaging-, and Laboratory-Based Assessments. Arthritis Care Res(Hoboken). 2020;72:1296-1304.

21. Lee KS, Ernst A, Trentham DE, Lunn W, Feller-Kopman DJ, Boiselle PM. Relapsing polychondritis: prevalence of expiratory CT airway abnormalities. Radiology. 2006;240:565-73.

22. Ernst A, Rafeq S, Boiselle P, Sung A, Reddy C, Michaud G, et al. Relapsing polychondritis and airway involvement. Chest. 2009;135:1024-30.

23. Yu C, Joosten SA. Relapsing polychondritis with large airway involvement. Respirol Case Rep. 2020;8:e00501.

24. de Montmollin N, Dusser D, Lorut C, Dion J, Costedoat-Chalumeau N, Mouthon L, et al. Tracheobronchial involvement of relapsing polychondritis. Autoimmun Rev. 2019;18:102353.

25. Behar JV, Choi YW, Hartman TA, Allen NB, McAdams HP. Relapsing polychondritis affecting the lower respiratory tract. AJR Am J Roentgenol. 2002;178:173-7.

26. Lin ZQ, Xu JR, Chen JJ, Hua XL, Zhang KB, Guan YJ. Pulmonary CT findings in relapsing polychondritis. Acta Radiol. 2010;51:522-6.

27. Slart R. FDG-PET/CT(A) imaging in large vessel vasculitis and polymyalgia rheumatica: joint procedural recommendation of the EANM, SNMMI, and the PET Interest Group (PIG), and endorsed by the ASNC. Eur J Nucl Med Mol Imaging. 2018;45:1250-69.

\section{Figures}




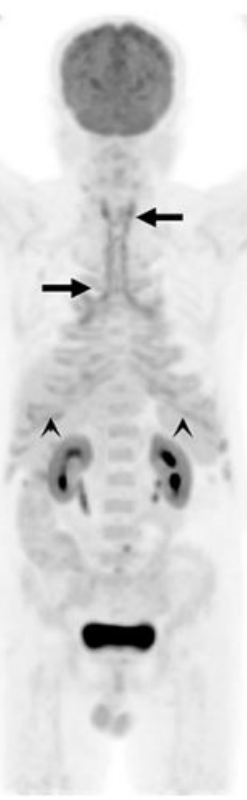

Patient 4

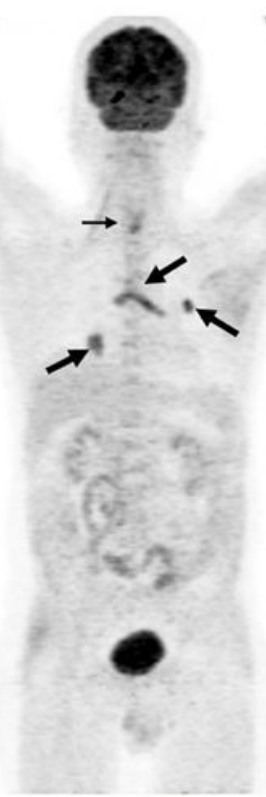

Patient 5

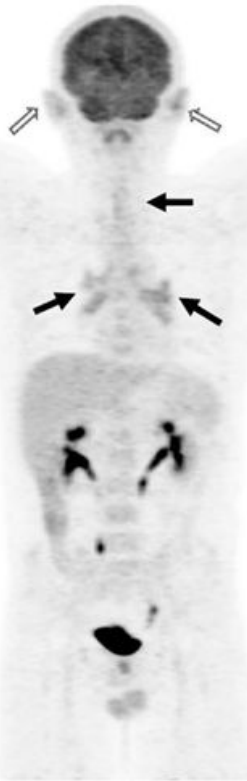

Patient 13

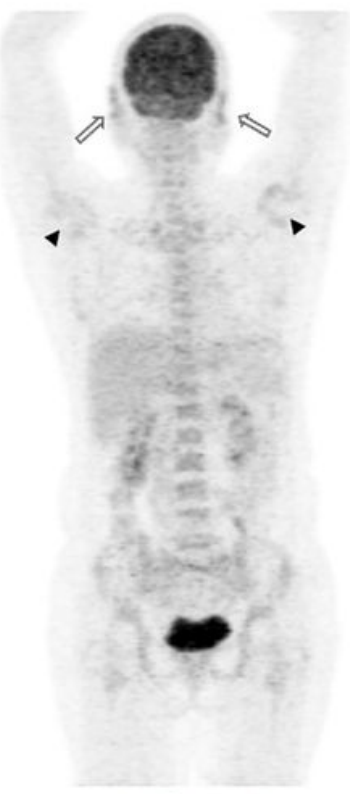

Patient 24

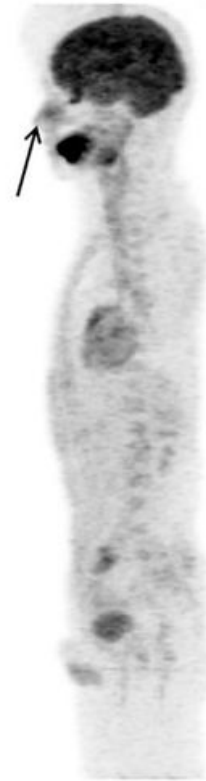

Patient 29

Figure 1

Representative cases of RP patients with airway involvement. FDG-avid laryngo-tracheo-bronchial tree involvement was shown in patients 13 , 24, and 29 (black arrows). Other involved sites include auricles (Patient 4, 29; hollow arrows), costicartilages (Patient 24; open arrowheads), bilateral shoulder joints (Patient 4; closed arrowheads) and nasal cartilage (Patient 5; long thin arrow).

(a)

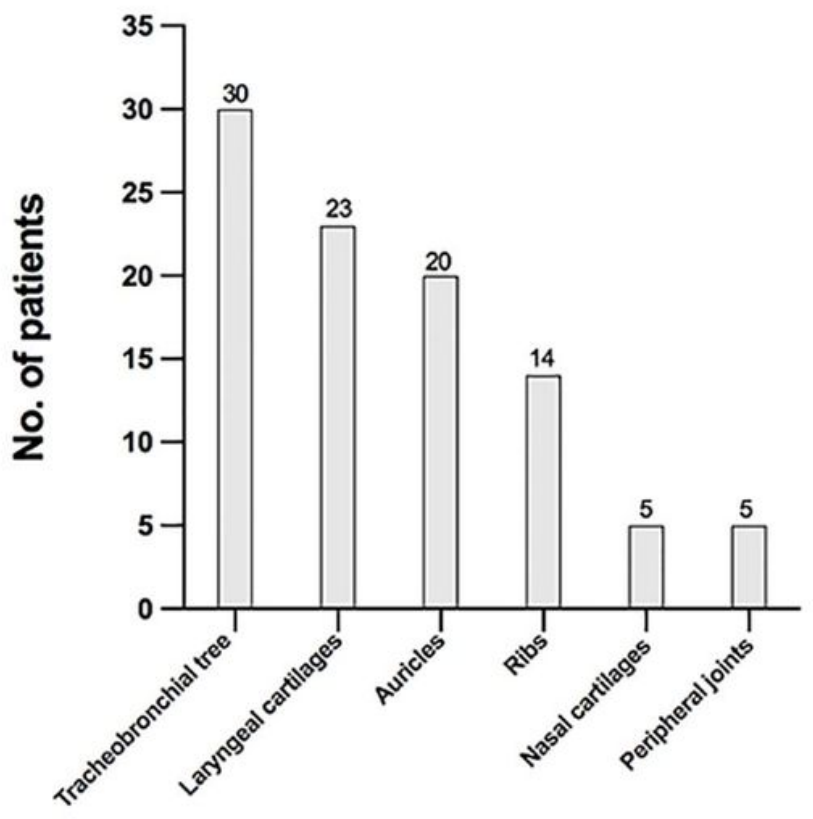

(b)

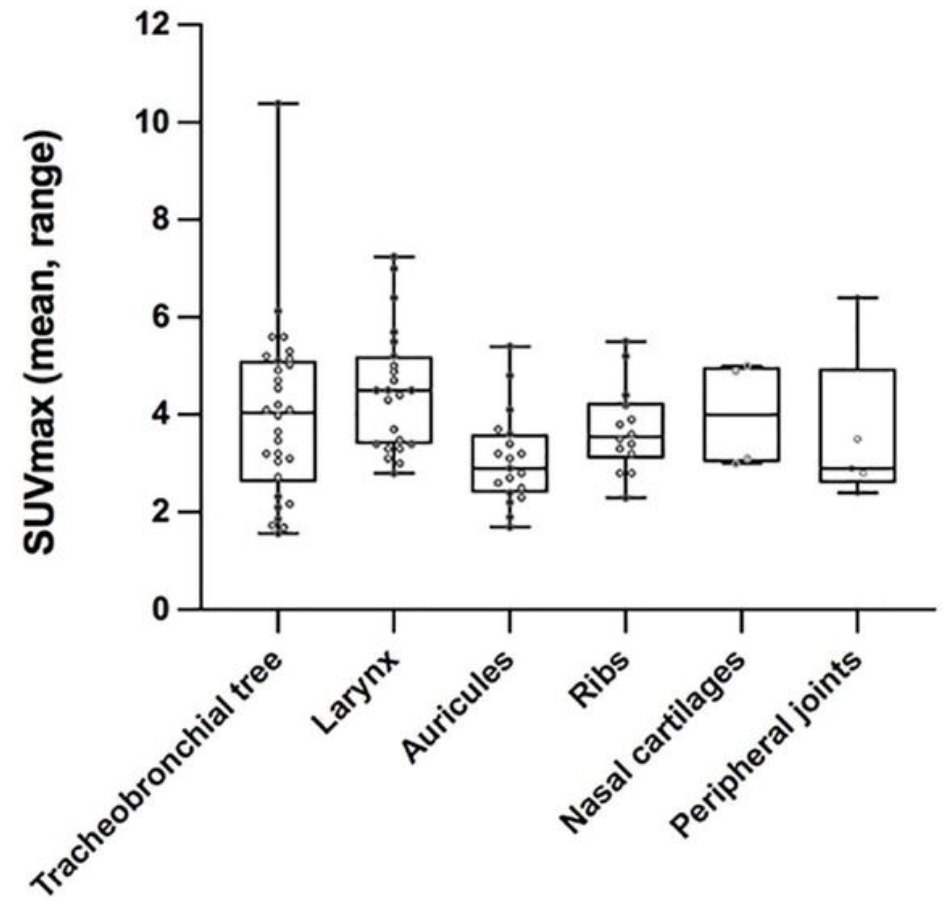

Figure 2

The frequency (a) and mean SUV $\mathrm{max}_{\text {max }}$ (b) of each involved site. As is shown, the most commonly affected site was trcheobronchia, followed by the larynx and auricules. The SUV $V_{\max }$ was lowest in the auricules and highest in the laryngeal cartilage. The SUV $\mathrm{max}_{\max }$ of the tracheobronchial tree showed the widest SUV range. 
(a)
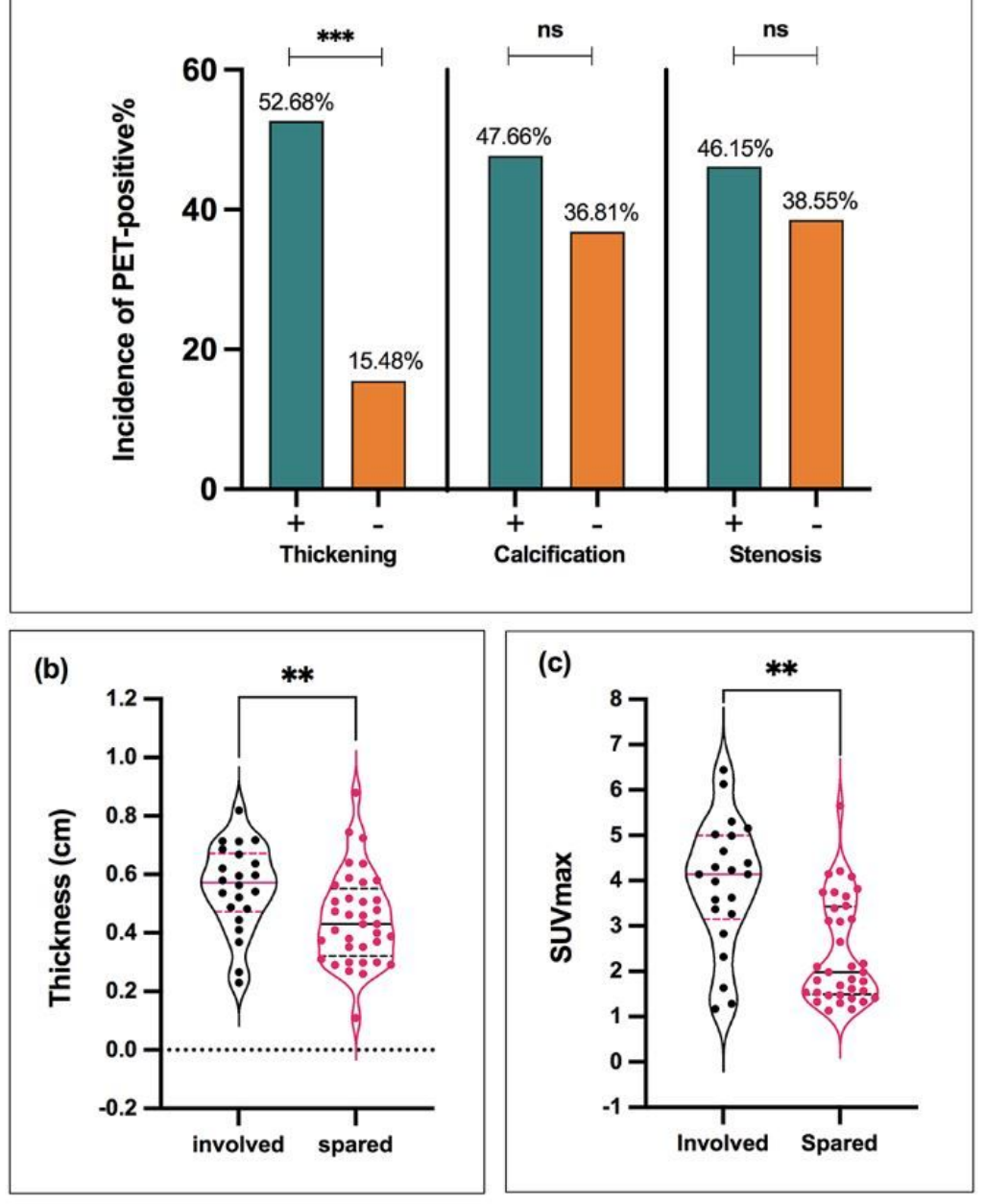

\section{Figure 3}

(a) Comparison of the incidence of PET positive rate among variable morphological abnormalities of the tracheobronchial tree. The graph shows a higher positive rate in patients with thickened walls but not with calcification or stenosis. Comparison of tracheal wall thickness (b) and SUV $\mathrm{Vax}_{\text {ma }}(\mathrm{c})$ with and without posterior wall involvement. Increased thickness and SUV ${ }_{\max }$ were revealed in patients with circumferential thickening, as demonstrated in the figure. 

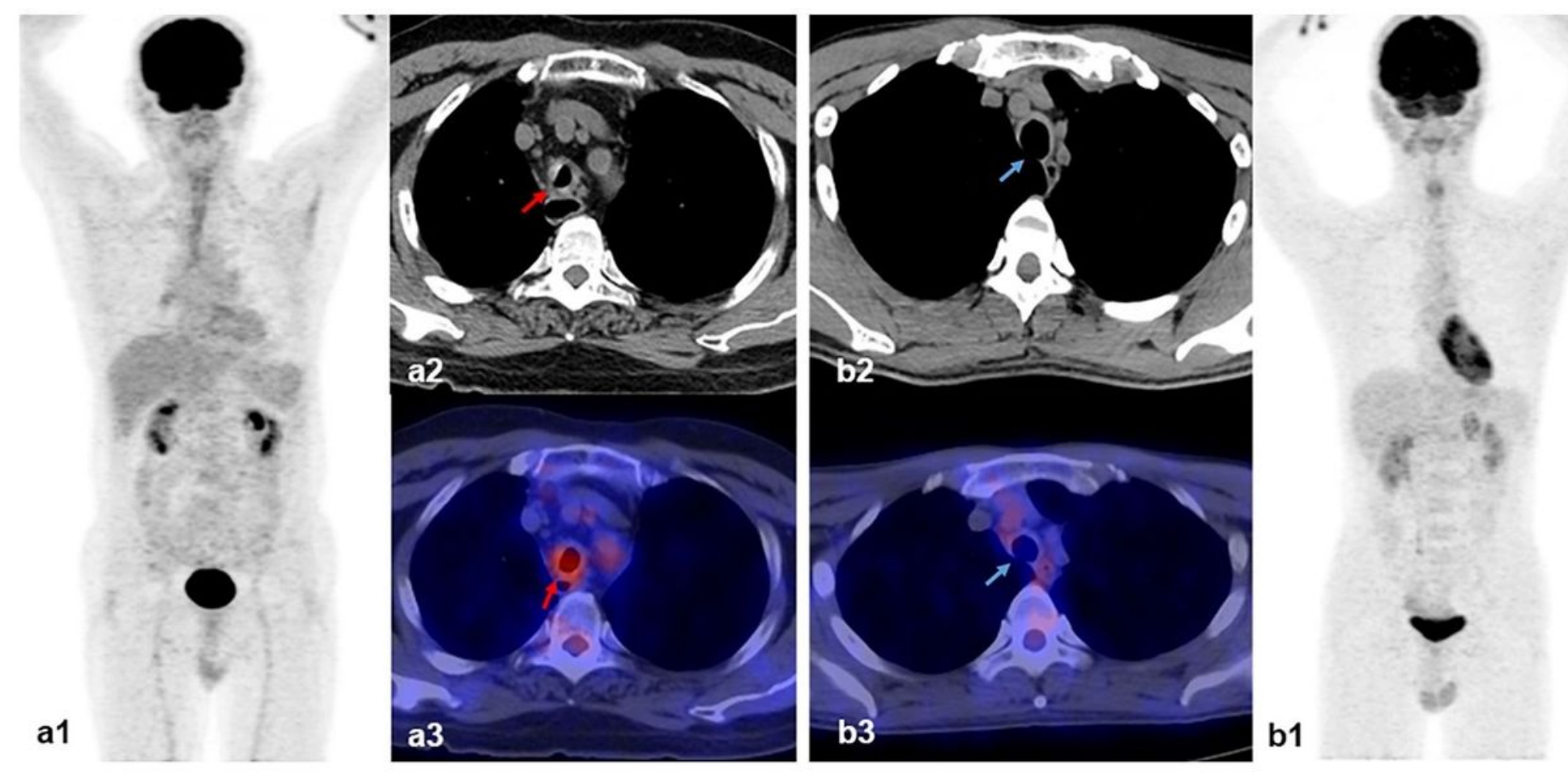

\section{Figure 4}

A 58-year-old man (a1-3) presented with cough for 9 months and suffered shortness of breath for a second time in recent days. MIP (a1) and fusion imaging (a3) demonstrated a ring-like increase of FDG uptake in the trachea. The corresponding CT (a2) showed circumferential thickening of the wall (red arrows). Figures on the right show a 36-year-old man who manifested as consistent shortness of breath for 6 months (b1-3). Although chest CT (b2) showed slight thickening of the anterior and lateral walls of the trachea, the uptake was not definite (b3). Note that the posterior wall was spared of thickening (blue arrows). 



Figure 5

Relationship of disease duration and airway/whole-body PET parameters. The longer duration, the lower FDG uptake. The Spearman correlation coefficient was superior to that of the PETFBS airway. 

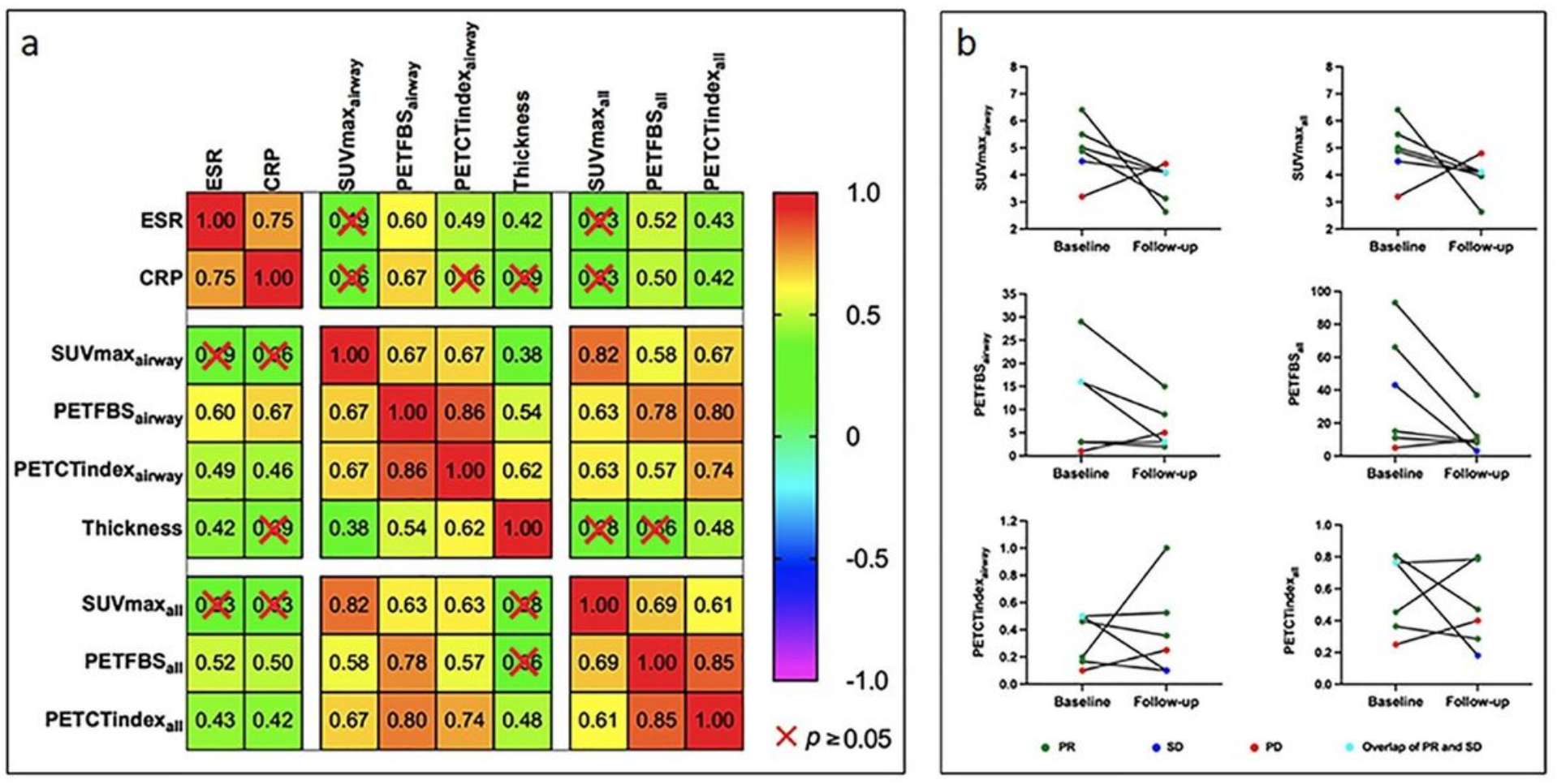

Figure 6

(a) Spearman correlation matrix between nine quantitative criteria. ESR and CRP showed the highest coefficient with PETFBS airway. (b) Change of follow-up PET/CT in 6 patients was demonstrated. All but one patient who was considered PR on PET/CT but SD clinically were consistent with the clinical evaluation.

\section{Supplementary Files}

This is a list of supplementary files associated with this preprint. Click to download.

- Additionalfile1.pdf

- Additionalfile2.pdf

- Additionalfile3.pdf

- Additionalfile4.pdf 